\title{
MASTERS-LEVEL TEACHER PREPARATION
}

\author{
AILEEN KENNEDY \& NICOLA CARSE
}

\author{
Aileen Kennedy, University of Edinburgh \\ aileen.kennedy@ed.ac.uk \\ Nicola Carse, University of Edinburgh \\ nicola.carse@ed.ac.uk
}

\section{Author/s Biography/ies:}

Aileen Kennedy is a Senior Lecturer at the University of Edinburgh, where she was responsible for the development of an innovative new two-year ITE Masters designed from an explicit transformative and activist stance. Her research focuses on teacher education, professional learning, teacher professionalism, and policy reform in these areas, and she is currently Co-Principal Investigator on a six-year, Scottish Government-funded project entitled 'Measuring Quality in Initial Teacher Education'. She is Managing Editor of Professional Development in Education, a member of the UK and Irish Teacher Education Group, and of the Global Teacher Education Consortium. Aileen regularly contributes to national working groups involved in developing teacher education policy, and works with groups of teachers and other educators within and beyond Scotland to develop their understanding of teacher learning. Along with Nicola Carse, she co-convenes the Scottish Educational Research Association's Teacher Education Network.

Nicola Carse is a Lecturer in Physical Education at the University of Edinburgh. Her research focuses on teacher education, professional learning, curriculum development, practitioner enquiry and selfstudy. Nicola is a co-investigator on a six-year, Scottish Government-funded project entitled 'Measuring Quality in Initial Teacher Education'. Nicola is currently the President of the Scottish Educational Research Association and co-convenes two affiliated networks, the Teacher Education Network and Scottish Physical Education Network.

This is an accepted manuscript of the following book chapter: Kennedy, A., \& Carse, N. (Accepted/In press). Masters-level teacher preparation. In R. Shanks (Ed.), Teacher Preparation in Scotland Emerald Publishing Limited. 


\section{ABSTRACT:}

This chapter explores the idea of Masters-level Initial Teacher Education (ITE), beginning by looking at the wider global context which reflects a drive towards increasing Masters-level ITE, but with limited empirical evidence as to its effectiveness and a variety of claims as to its potential impact. It then goes on to examine aspects of the policy context in Scotland that are influence a growing move towards increased Masters-level ITE. This is followed by an overview of current practices, identifying three broad approaches: credits in courses, integrated Masters and full Masters. The chapter concludes by suggesting that while the direction of travel is clear, the underpinning rationale is much less so.

\section{KEYWORDS:}

1. Masters-level

2. Initial teacher education 


\section{Introduction}

All initial teacher education in Scotland is currently degree-level and university-based, however, in a wholesale review of teacher education, while not advocating for a full 'Masters profession', Donaldson (2011) highlighted the central role that advanced, postgraduate-level study contributes to enhanced professionalism and the provision of quality professional development for teachers (10). Over the past decade, policy interest in a 'Masters profession' has increased and has seen a range of responses from local authorities, universities and bodies such as the General Teaching Council for Scotland (GTCS), with an increase in Masters-level learning opportunities at post-qualification stage, but also, increasingly, within initial teacher education (ITE). This chapter focuses specifically on the growth in Masters-level learning within initial teacher education, but this is, inevitably, set within a wider narrative of teacher learning.

Before going any further, however, it is important to outline how Masters-level is defined in Scotland. All qualifications are mapped against the 'Scottish Credit and Qualifications Framework' (SCQF) (www.scaf.org.uk) which comprises 12 levels: Level 10 equates to Honours Degree level, Level 11 to Masters level and Level 12 to Doctoral level. Each level is defined through descriptors organised under five categories:

- Knowledge and understanding;

- Practice (applied knowledge and understanding);

- Generic cognitive skills (e.g. Evaluation, critical analysis);

- Communication, numeracy and it skills; and

- Autonomy, accountability and working with others.

Descriptors for Level 11 include ideas such as 'critical understanding', 'originality', 'creativity', and managing 'complex professional and ethical issues' (SCQF, 2012: 28). So, with an emphasis on criticality, complexity and intellectual autonomy, it is easy to see how these skills might usefully be deployed in teaching, and while the shift towards a 'Masters profession' therefore suggests many opportunities for teaching as a profession, it should not be accepted uncritically. Over the last twenty years, teacher quality has received increased interest in education policy (see Stecher et al., 2018; OECD, 2005; Barbour \& Mourshed, 2007). Darling Hammond (2017) suggests that this increased interest can be attributed to the perception of an inextricable link between teacher quality and student achievement. Thus, the unquestioned link between these factors has resulted in increased policy interest in improving teachers, their work and teacher education.

Focusing specifically on initial teacher education it is possible to see an emerging international pattern of significant change and reform (Cochran-Smith et al., 2018). This reform narrative has been prompted by concerns about both teacher quality and teacher shortages, leading to increased interest in more flexible, alternative routes into teaching. It should be noted, however, that these two concerns do not naturally imply the same set of solutions. Menter (2017) suggests that the changes in initial teacher education internationally can be characterised into two tendencies: 'one to increase the input and involvement of higher education ("the university turn"), the other to reduce that contribution and to emphasise the importance of practical experience in school ("the practical turn")' (2). These two 'turns' could, arguably, although perhaps a little simplistically, be seen to satisfy the different requirements of the two concerns expressed above: one focusing on quality and one on supply. Furthermore, Cochran-Smith (2005) suggests the emergence of a 'new teacher education', receiving increased policy scrutiny, driven by outcomes, but also emphasising the central role of research and evidence. This 'new teacher education' has both positive and negative implications where the emphasis placed on research highlights the role of advanced study as part of teacher professionalism, 
while the outcomes and evidence focus, combined with teacher shortages, has led to alternative routes into teaching which by-pass universities, in favour of learning 'on the job'.

These shifting university and practical discourses shaping contemporary ITE accentuate the complex and challenging process of designing and delivering ITE, and the centrality of partnership between universities and schools. While internationally there has been a rise in practice-based routes into teaching such as Teach First, Teach for All and 'School-Centred Initial Teacher Training' (SCITT), much of the literature and recent studies into effective teacher education highlights the crucial contribution of both schools and universities, combining experiential learning with knowing and understanding educational theory (Moon 2016; Furlong 2013; Burn and Mutton, 2013; Darling Hammond, 2012; Mayer et al., 2015). This emphasis on well-considered school and university partnership, combined with a Europe-wide elevation of the qualifications level to become a teacher and growing interest in research and teaching, has contributed to the Masters discourse currently prevalent within ITE.

\section{Debating Masters-level ITE in the wider context}

As outlined above, over recent years, demands for increased quality and quantity of teachers have increased in parallel, resulting in a context that both values advanced study whilst at the same time craving quick fix answers to producing teachers. We suggest that this context has fuelled the emergence of Masters-level ITE, within which a variety of approaches has been developed. For example, through the introduction of Masters credits in ITE courses such as the Postgraduate Certificate in Education (PGCE) in England and Professional Graduate Diploma in Education (PGDE) in Scotland respectively (Dickson, 2011; Brooks, Brant, Abrahams \& Yandell, 2012). This approach means that students graduate with a certain number of Masters-level credits which they can then build on in working towards a full Masters post-qualification should they wish to. Contrastingly, in some European nations, for example in Finland and Germany, all new teachers are required to complete a 2-year Masters qualification, in addition to an undergraduate degree, before entering teaching (Sabrin, 2018; Darling-Hammond, 2017).

In addition to this range of approaches to Masters-level ITE, there are also varying perspectives on its value. Heilbronn and Yandell (2010) argue that Masters-level learning in ITE promotes research literacy, intellectual engagement and critical reflection. Similarly, Thomas (2018) identifies two common themes from her research into teacher educators' and student teachers' perspectives of the value of Masters-level ITE within two HEl contexts in England: that it enhanced knowledge and practice, and the intellectual enjoyment of working at this academic level. These positive perspectives of Masters-level ITE resonate with the shift to emphasise the role of advanced study in teacher professional learning as outlined by Cochran-Smith (2005). Furthermore, considering these positive aspects in relation to Finland, one of the most commonly cited proponents of a Masters-level teaching profession, it is possible to see how the value placed on research, critical reflection and linking theory to practice has contributed significantly to creating a teaching profession that is highly respected and supported. Darling-Hammond (2017) highlights how teacher education in Finland positions teachers as researchers and research users, which ultimately contributes to affording considerable autonomy to the profession. However, while we use Finland as a positive example, we must be cautious about the challenges of policy borrowing, and the need to consider wider societal, cultural and contextual factors and the impact they have on education systems (Phillips \& Ochs, 2010).

Whilst it is evident that Masters-level ITE has the potential to engage pre-service teachers and support them to integrate theory and practice in a genuine way, there are some challenges to positioning ITE as Masters-level. Reflecting on Masters-level study in a PGCE programme within an English university, Brooks et al. (2012) identified that a number of students viewed Masters-level study as contributing to career progression, which for beginning teachers is understandable and reflects other similar 
research by Creasor (2008). However, within the context Brooks et al. (2012) were researching, some students were placing emphasis on career advancement from Masters-level study rather than on its capacity to enhance teaching practice. This finding indicates a possible point of tension for including Masters-level study in ITE, particularly when one of the perceived benefits is making links between theory and practice. This tension also reflects concerns raised that ITE students lack the teaching experience required to engage in meaningful professional Masters-level learning. This critique argues that the critical reflection on practice in relation to policy and theory required at Masters-level necessitates immersion within a school context and extensive teaching experience (Burton \& Goodman, 2011; Thomas, 2018). While undoubtedly a challenge, Darling-Hammond's work on 'powerful programs' (2006) suggests that this integration of theory and practice is possible through extended site-based learning during ITE: 'The most powerful programs require students to spend extensive time in the field throughout the entire program, examining and applying the concepts and strategies they are simultaneously learning about in their courses' (ibid., 307).

A further critique raised about Masters-level ITE is in relation to 'the ongoing debate over the nature, purpose and usefulness of educational research itself' (Gray, 2013: 24). Considering the hybrid positioning of the teacher/researcher, Gray (2013) highlights a critique of practitioner research from scholars such as Gorard (2002) and Foster (1999), which questions the rigour of practitioner research. Linking this to Masters-level study in ITE, it highlights the need for research knowledge, understanding and skills to be developed during teacher education, and questions the extent to which this is possible within the context of ITE (Thomas, 2018; Gray, 2013; Brooks et al., 2012). This critique is further supported by literature that questions the transferability into practice of the skills, knowledge and research experience gained from Masters-level study (Reis-Jorge, 2007; Borg, 2010; Volk, 2010). While these critiques raise valid concerns about the positioning of Masters-level study in ITE, they can equally be countered by the literature highlighting the value of Masters-level study. Central to the positive impact of Masters-level learning is its transformative potential as highlighted by Brooks et al. (2012) who emphasise the process of professional learning that Masters-level study immerses student teachers in, and how this supports an ongoing orientation towards transformative teaching and learning.

This introduction has sought to provide the international backdrop for the concept of a Masters teaching profession. The following sections will now focus on the Scottish context - first looking at the policy context shaping Masters-level ITE in Scotland, and then looking at how this has played out in practice.

\section{Masters-level ITE in Scotland: the policy context}

Although not going as far as to pronounce that Scotland should work towards a fully Masters-qualified teaching profession, the Donaldson Report (2011) set the context for a more explicit narrative of career-long Masters-level learning for all teachers. However, the place of Masters-level learning in ITE has been a little more complex to trace. ITE in Scotland became a full Bachelor's degree profession in the 1980s, and by the end of the twentieth century, all ITE provision in Scotland was based in universities, following a series of mergers between the former independent teacher education colleges with local universities (see chapter 3 and Hulme and Menter, 2013, for further detail). And while Donaldson (2011) did recommend that 'Masters level credits should be built into initial teacher education qualifications, induction year activities and CPD beyond the induction year, with each 
newly-qualified teacher having a 'Masters account' opened for them' (99), in reality, Masters-level credits had gradually been creeping into the one-year Professional Graduate Diploma in Education (PGDE) programmes across Scotland for some time.

More recently, a number of policy developments have raised the prominence of Masters-level ITE more explicitly, including: a call for what the Cabinet Secretary for Education, John Swinney, called 'new and innovative routes'; a report on potential new career pathways for teachers; and a review of the current 'Scottish Framework for Masters in Education'. These policy developments are each discussed below, after which follows an overview of the current picture vis-à-vis Masters-level ITE. This is followed by a discussion of the extent to which these policy developments, and the resulting practice in terms of ITE programme provision, reveal a shared understanding of what M-level ITE is and can achieve.

\section{A call for new and innovative ITE routes}

In 2016, John Swinney, the Cabinet Secretary for Education and Deputy First Minister of Scotland, invited ITE providers to respond to a number of challenges by offering what he called 'innovative new ways of developing teachers' (Scottish Government, 2016). The challenges precipitating this call included issues of both quality and quantity of teachers, and included a challenge to ITE providers to provide opportunities for teachers to complete a full Masters degree during ITE or the induction year, as well as to find ways to diversify the teacher workforce and provide routes that would get more teachers into the system more quickly, particularly in shortage areas. This agenda mirrors the international context as outlined above, where both the 'university turn' and the 'practical turn' (Menter, 2017) are implicated, but are not necessarily compatible. Responses to this call, in which Scottish Government has invested $f 1$ million, have resulted in the previously rather conservative and homogenous ITE provision diversifying, revealing a wider range of (sometimes contradictory) underpinning rationales at play.

\section{Career pathways report}

In June 2018 a review group was established to consider and make recommendations regarding career pathways for teachers in Scotland (https://www.gov.scot/groups/career-pathways-for-teachersindependent-panel/). One of its tasks was to explore 'the link between career pathways and qualifications (e.g. masters level learning or new forms of initial teacher education)'. In May 2019, the report was published, and amongst the ten recommendations was one which pertained to an aspiration to enhance Masters-level learning: 'Further steps should be taken to promote teaching as a Masters profession whilst recognising the importance of work-based professional learning and experience.' (Scottish Government, 2019: 4).

However, this recommendation was not just in relation to post-qualification professional learning; for the first time, an unequivocal national statement was made outlining an aspiration for all ITE programmes to provide the opportunity for students to engage in Masters-level learning:

'The Panel is of the view that all universities, as their ITE programmes are reaccredited or new programmes and routes into teaching are developed, should offer the opportunity for students to engage with masters learning, though not necessarily to study full masters qualifications. This would allow teachers to begin building a pathway 
to masters qualification at the start of their careers. Further study throughout a teacher's career should build on their Higher Education experience and align to their chosen career pathway. Such opportunity for progression with academic study would require the continuation and strengthening of existing partnerships between universities, local authorities and GTCS'. (Scottish Government, 2019: 15)

While, at the time of writing, the report is still under consideration by the Scottish National Committee for Teachers (SNCT) - the joint negotiating group for teachers' pay and conditions - it is highly significant in policy terms that this pronouncement has been made.

\section{Masters framework review}

The Strategic Board for Teacher Education was created in 2016 to provide coherence and oversight to policy decisions relating to teacher education at all career stages. In 2018 it set up a short-life working group to review the existing 'Scottish Framework for Masters in Education'. This review was an attempt to make the current landscape more coherent for teachers, to enable them to see more clearly how and where they could access Masters learning and how they could make use of existing credits gained through ITE or other Scottish Government-funded Masters learning opportunities. Of course, the extent to which this landscape can be made more coherent depends largely on the extent to which universities can align their institutional regulations, and this highlights one of the challenges of the Masters-level profession as opposed to a Masters-qualified profession. Whilst the framework is perhaps currently of more pertinence to post-qualification teachers, the ever-increasing range of ways in which ITE programmes incorporate Masters credits, coupled with the policy aspiration for ITE discussed above in relation to the career pathways report, the policy trajectory looks to be travelling in an unstoppable direction towards greater Masters-level content across all ITE programmes. Thus, the alignment between ITE and post-qualification professional learning becomes even more critical.

\section{Masters-level ITE: the current picture}

The previous section outlines the policy context in Scotland that has led to the current position vis-àvis Masters-level ITE and reveals a somewhat messy picture. This section attempts to explain and map this provision, suggesting that current developments can be categorised into three broad structural approaches: credits in courses; integrated Masters; and full Masters.

\section{'Credits in courses'}

Since the early-mid 2000s, most PGDE programmes in Scotland have incorporated some Masters-level credits (SCQF Level 11), the remaining credits being at SCQF Level 10 (equivalent to honours degree level). There are currently PGDE programmes across ten of the eleven ITE higher education institutions in Scotland, each programme comprising 120 credits (60 ECTS credit points). Of these 120 credits, all programmes offer some Masters-level credits ranging from 10 to 120 , with most sitting in the $60-90$ Masters-level credit range. It is reasonable to assume that to some extent this is about sector competitiveness, but the underpinning rationale for the amount and structure of Master-level credits in these PGDE programmes is not always publicly stated. In the case of the University of Glasgow, a clear case has been made by Dickson (2011) in terms of the need 'to form in beginning teachers new 
ways of thinking about teaching enabling them to take an enquiry stance towards teaching which consists of the ability to systematically evaluate and improve their own practice' (265).

Elsewhere, a commonly held view of the reason for M-level credits in PGDE programmes is that it gives students a 'taster' of Masters study, and provides a route towards further Masters study postqualification, thereby helping to fulfil the national agenda promoted by Donaldson (2011), but further consolidated in the National Improvement Framework (Scottish Government, 2019). The National Improvement Framework, the Scottish Government's way of measuring and accounting for education policy success, uses the number of teachers gaining Masters-level qualifications as one measure of enhanced 'teacher professionalism'. In the National Improvement Framework, published annually since 2015, the Scottish Government continues to reiterate its commitment to providing some funding for post-qualification Masters learning for teachers.

Not only does the number of Masters-level credits within PGDE programmes vary, but so too does the status of these credits, that is, in some programmes the Masters-level credits are compulsory and in some they are optional. Some programmes offer students the opportunity to be assessed at either Level 10 or at Masters-level. In terms of teaching, this is potentially problematic in that it is unclear whether the modules in question are being taught at Masters level, or whether they are taught at Level 10 and then students are expected to raise their engagement to Masters-level when preparing work for summative assessment. The issue of Masters-level teaching is complex, and not always grappled with openly. For example, would a teacher educator/tutor/mentor without a Masters qualification be sufficiently well-prepared to teach at this level?

The progressive move towards more Masters-level credits in PGDE courses seems to highlight a clear and ongoing direction of travel, that one might assume will likely end in full Masters-level postgraduate diploma programmes, yet underneath this seemingly clear direction of travel lies a mixed economy of teaching and learning at different levels, and a level of complexity and confusion in terms of the individual rationales and structures for Masters-level learning (or simply Masters-level assessment?) in PGDE programmes. Reflecting on the earlier discussion about findings which indicated that some ITE students valued Masters-level credits more as career progression tokens than as a means of enhancing their own learning and practice (Creasor, 2008; Brooks et al., 2012), it seems important going forward that the rationale for the structure of Masters-level credits within PGDE programmes is made explicit, is well-argued, and is supported by appropriately qualified staff.

\section{'Integrated Masters'}

Perhaps inevitably, given the increasing creep towards greater numbers of Masters-level credits in PGDE programmes, we are beginning to see the emergence of integrated Masters in ITE. The University of Glasgow has introduced a five-year 'MEduc', designed as a continuous five-year programme of study, the fifth year of which is undertaken part-time whilst employed as an induction year teacher. Students can exit at the end of four years with an Honours degree and a teaching qualification (the traditional exit point at the end of the fourth year allows students to treat the pathway as an undergraduate route into teaching). However, the standard expectation is that students would typically complete five years of study: a fourth year student opts to 'exit', rather than opts to 'continue'. This integrated Masters degree has been conceptualised as a 'third type' of degree. In other words, it is not BEd + MEd, but a cohesive and fully integrated degree structure, where students are intended to progress seamlessly from SCQF L7 to SCQF L11, culminating in the completion 
of a full Masters dissertation. Whilst an Integrated Masters does not follow a traditional postgraduate taught structure, it concludes at the same level of academic challenge.

In a similar vein, the University of Strathclyde now offers an integrated PGDE/MEd for STEM teachers which combines the one-year PGDE and induction year in the same school alongside studying for the remainder of the MEd degree. Designed to attract STEM graduate career-changers, the Masters element here is in part designed to lure STEM graduates into teaching rather than into other, potentially higher paid and higher status jobs. Thus, again we see Masters-level ITE also functioning as status enhancing, arguably being used to address the challenge of teacher quantity rather than teacher quality.

So, when integrated Masters are added to an already complex variety of PGDE routes with Masters credits, and further progression routes once qualified, the choices for partial masters study in ITE are becoming very wide-ranging indeed, hence the move by the Strategic Board for Teacher Education to review the current Scottish Framework for Masters in Education in an attempt to make pathways clearer to teachers wishing to continue or begin Masters-level study.

\section{'Full Masters'}

Given the direction of travel outlined above, it is perhaps no surprise that we are also now beginning to see full Masters-level ITE programmes emerging. The University of Edinburgh offers a two-year (21month) MSc Transformative Learning and Teaching degree which qualifies graduates to teach either as generalists across nursery to secondary year 3 , or as subject specialists from primary 5 to secondary 6. This programme is based on an explicit transformative perspective, supporting graduates who see teaching as social justice work to adopt explicitly activist dispositions. The rationale for this programme being at Masters level is that in order to engage in truly transformative learning, students need to be able to engage in critical reflection in the way that Dewey $(1933$, p. 118) defined it, as 'active, persistent and careful consideration of any belief or supposed form of knowledge in the light of the grounds that support it and the further conclusion to which it tends'. Critical reflection, and the capacity to interrogate and challenge one's own assumptions sits squarely within the SCQF descriptors of Masters-level study, and supports the findings in Thomas' (2018) study that highlight both the support for developing criticality and the intellectual satisfaction of Masters-level ITE.

The University of Glasgow offers an MEd Middle Years. This is a 180-credit (equivalent to 90 ECTS credits) postgraduate Masters-level programme spanning 18 months, and qualifying teachers to work in primary schools and, with the appropriate undergraduate degree, to teach their subject - currently maths or science - in the first three years of secondary school. With the Glasgow PGDE programmes currently calibrated at 90 credits of academic study at Level 11 and 30 credits of school experience at Level 10 (120 credits in total) it seems logical that a programme that prepares graduates to teach across a wider range of levels, and includes more subject specialisation than the PGDE Primary does, should be longer, and therefore comprise more credits. This is perhaps a somewhat technical-rational reason for the Masters level nature of the programme, but does illustrate how changing one part of the system, e.g. the introduction of Masters-level credits in PGDE programmes, inevitably has a knockon effect on other parts of the system.

\section{Masters-level learning - a shared view?}


The above overview of current provision has outlined Masters-level provision under three broad structural categories:

- Credits in courses

- Integrated Masters

- Full Masters

It is worth noting that the integrated and full Masters programmes are a much more recent policy development than the 'credits in courses' approach, but is clear that Scottish ITE is on a trajectory towards increased Master-level credit in ITE programmes. Both within and across these three different structural categories, there appears to be no one clear and shared vision of why this agenda is being pursued. While an explicit rationale for some programmes is publicly available, this is not the case for all. Even without explicit, public statements outlining the underpinning rationale, it seems obvious that the different amounts, structures and status of the Masters-level learning suggests a range of different rationales at play. This is probably in large part due to the fact that the origins of the drive towards a Masters-level teaching profession in Scotland are not easy to trace, arguably coming from several different sources. First there is the global meta-narrative around teacher quality which pushes nations into ratcheting up the level of their ITE in an attempt to maintain global competitiveness, without any evidence to support the ideas that increasing the academic level of a qualification results in better teaching (Brooks et al., 2012; Howe, 2013) Second, there is the rationale that supports Master-level learning as a means of enhancing teachers' capacity to think critically, thereby informing their practice in a more nuanced and thoughtful way (Thomas, 2018). Third, there is the capacity for Masters-level learning to support a more research literate and engaged teachers (Heilbronn and Yandell, 2010). And finally, Masters-level ITE can be used to attract people into the teaching profession by way of its appeal to the narrative of career progression (Brooks et al., 2012). It appears that all of these purposes are evident in our current provision, but with differences across programmes in the particular local focus.

Going back to the discussion at the beginning of the chapter, the twin issues of quality and quantity were highlighted as key drivers for the growth in Masters-level ITE. Clearly, if a programme rationale relates to the understanding that Masters-level ITE can better equip teachers to think critically, to use this to shape their practice and to work in research literate and research-engaged ways, then this clearly plays into the quality agenda. To see Masters-level provision as a means to attract more, or 'better' students to become teachers is more about addressing the quantity issue. The neoliberal global competition narrative could be seen to support the quality issue, but there remains scant evidence that Masters-level ITE raises the quality of graduates in a wholesale way. Thus, we conclude that while the direction of travel is clear, the reasons for that journey are not, and would benefit from deeper interrogation and discussion across the stakeholder community.

\section{References:}

Barber, M., \& Mourshed, M. (2007). How the world's best-performing schools systems come out on top. McKinsey \& Company.

Borg, S. (2010). Language teacher research engagement. Language Teaching, 43(4), 391-429.

Brooks, C., Brant, J., Abrahams, I. \& Yandell, J. (2012). Valuing initial teacher education at Master's level. Teacher Development, 16(3), 285-302. 
Burn, K. \& Mutton, T. (2013). Review of 'research-informed clinical practice' in initial teacher education. Research and teacher education: The BERA-RSA Inquiry. Retrieved from: https://www.bera.ac.uk/wp-content/uploads/2014/02/BERA-Paper-4-Research-informed-clinicalpractice.pdf

Burton, D. \& Goodman, R. (2011) The Masters in Teaching and Learning: a revolution in teacher education or a bright light quickly extinguished? Journal of Education for Teaching, 37(1), 51-61.

Cochran-Smith, M. (2005). The new teacher education: For better or for worse? Educational researcher, 34(7), 3-17.

Cochran-Smith, M., Stringer Keefe, E., \& Carney, M. C. (2018). Teacher educators as reformers: Competing agendas. European Journal of Teacher Education, 41(5), 572-590.

Creasor, C. (2008). A Master's level profession? The mid-course views of PGCE trainee teachers (unpublished paper). Edge Hill: Edge Hill College.

Darling-Hammond, L. (2006). Powerful Teacher Education: Lessons from Exemplary Programs. San Francisco, CA: Jossey-Bass.

Darling-Hammond, L. (2012). Teacher preparation and development in the United States: a changing policy landscape. In L. Darling-Hammond \& A. Lieberman (Eds.), Teacher education around the world (pp. 130-150). London: Routledge.

Darling-Hammond, L. (2017). Teacher education around the world: What can we learn from international practice? European Journal of Teacher Education, 40(3), 291-309.

Dewey, J. (1933). How We Think: A Restatement of the Relation of Reflective Thinking to the Educative Process. Boston, MA: D.C. Heath \& Co Publishers.

Dickson, B. (2011). Beginning teachers as enquirers: M-level work in initial teacher education. European Journal of Teacher Education, 34(3), 259-276.

Donaldson, G. (2011). Teaching Scotland's Future: Report of a review of teacher education in Scotland. Scotland: Scottish Government.

Foster, P. (1999). 'Never mind the quality, feel the impact': A methodological assessment of teacher research sponsored by the Teacher Training Agency. British Journal of Educational Studies, 47(4), 380398.

Furlong, J. (2013). Education - an Anatomy of the Discipline: Rescuing the university project? London: Routledge.

Gorard, S. (2002). Political control: A way forward for educational research? British Journal of Educational Studies, 50(3), 378-389.

Gray, C. (2013). Bridging the teacher/researcher divide: Master's-level work in initial teacher education. European Journal of Teacher Education, 36(1), 24-38.

Heilbronn, R. \& Yandell, J. (Eds.) (2010). Critical practice in teacher education: A study of professional learning. London: Institute of Education.

Howe, E. R. (2013). Alternatives to a master's degree as the new gold standard in teaching: A narrative inquiry of global citizenship teacher education in Japan and Canada. Journal of Education for Teaching: International Research and Pedagogy, 39(1), 60-73. 
Hulme, M. \& Menter, I. (2013). The Evolution of Teacher Education and the Scottish Universities. In Bryce, T.G.K., Humes, W.M, Gillies, D. \& Kennedy, A. (Eds.). Scottish education: fourth edition. Edinburgh: Edinburgh University Press, 905-914.

Mayer, D., Allard, A., Bates, R., Dixon, M., Doecke, B., Kline, J., Kostogriz, A. et al. (2015). Studying the Effectiveness of Teacher Education (Final Report). Geelong: Deakin University.

Menter, I. (2017). The Role and Contribution of Higher Education in Contemporary Teacher Education. Scottish Council of Deans of Education. /URL: http://www.scde.ac.uk/wpcontent/uploads/2017/05/Report-lan-Menter-2017-05-25. pdf.

Moon, B. (Ed.). (2016). Do Universities have a Role in the Education and Training of Teachers? Cambridge: University Press.

OECD (Organisation for Economic Cooperation and Development). (2005). Teachers Matter: attracting, developing and retaining effective teachers. Paris: OECD Publishing.

Phillips, D. \& Ochs, K. (2010). Processes of policy borrowing in education: some explanatory and analytical devices. Comparative Education, 39(4), 451-461.

Reis-Jorge, J. (2007). Teacher conceptions of teacher-research and self-perceptions as enquiring practitioners: A longitudinal case study. Teaching and Teacher Education 23, 402-417.

Sabrin, M. (2018). Elementary Teacher Education in the Top Performing European TIMSS Countries: A Comparative Study. International Education Studies, 11(4), 152-162.

Scottish Government (2016). New routes into teaching (Press Release). Edinburgh: Scottish Government. https://www.gov.scot/news/new-routes-into-teaching/

Scottish Government (2019). Independent panel on career pathways for teachers: final report. Edinburgh: Scottish Government.

Stecher, B., Holtzman, D., Garet, M., Hamilton, L., Engberg, J., Steiner, E., Robyn, A., Baird, M., Gutierrez, I., Peet, E., Brodziak de los Reyes, I., Fronberg, K., Weinberger, G., Hunter, G. \& Chambers, J. (2018). Improving Teaching Effectiveness: Final Report: The Intensive Partnerships for Effective Teaching Through 2015-2016. Santa Monica, CA: RAND Corporation. https://www.rand.org/pubs/research_reports/RR2242.html.

Thomas, L. (2018). The value of the academic award in initial teacher education: key stakeholder perceptions of the masters level Postgraduate Certificate in Education in two English universities. European Journal of Teacher Education, 41(2), 246-261.

Volk, K.S. (2010). Action research as a sustainable endeavour for teachers: Does initial training lead to further action? Action Research 8(3), 315-333. 